\title{
Peroral (POEM) or surgical myotomy for the treatment of achalasia: a systematic review and meta-analysis
}

\author{
Rafael Krieger MARTINS'1, Igor Braga RIBEIR0'1, Diogo Turiani Hourneaux DE MOURA',2, \\ Kelly E HATHORN ${ }^{2}$, Wanderley Marques BERNARDO ${ }^{1}$ and Eduardo Guimarães Hourneaux DE MOURA ${ }^{1}$
}

ABSTRACT - Background - Achalasia is a neurodegenerative motility esophageal disorder characterized by failure of lower esophageal sphincter relaxation. The conventional treatment option for achalasia has been laparoscopic Heller myotomy (LHM). However, in 2010, Inoue et al. described peroral endoscopic myotomy (POEM), a minimally invasive procedure, as an alternative therapy. To date, some studies with small sample sizes have aimed to compare outcomes of LHM vs POEM. Objective - Thus, the aim of this study is to perform a systematic review and meta-analysis to better evaluate the efficacy and safety of these two techniques. Methods - Individualized search strategies were developed from inception through April 2019 in accordance with PRISMA guidelines. Variables analyzed included operative time, overall adverse events rate, post-procedure gastroesophageal reflux disease (GERD), hospitalization length, post-procedure pain score, and Eckardt Score reduction. Results - Twelve cohort trials were selected, consisting of 893 patients (359 in POEM group and 534 in LHM.) No randomized clinical trials were available. There was no difference in operative time (MD $=-10,26,95 \%$ CI $(-5,6$ to 8,2$), P<0.001)$ or Post-Operative Gastroesophageal Reflux (RD: $-0.00,95 \%$ CI: $(-0.09,0.09)$, I $\left.{ }^{2}: 0 \%\right)$. There was decreased length of hospital stay for POEM (MD: -0.6, 95\% CI (-1.11, -0.09), $P=0.02)$, and an increased mean reduction in Eckardt score in POEM patients ( $\mathrm{MD}=-0.257,95 \% \mathrm{CI}$ : (-0.512 to -0.002$), P=0.048)$, with similar rates of adverse events. Conclusion - POEM demonstrated similar results compared to laparoscopic Heller myotomy with regards to improvement of dysphagia, post-procedure reflux, and surgical time, with the benefit of shorter length of hospital stay. Therefore, POEM can be considered an option for patients with achalasia.

HEADINGS - Esophageal achalasia. Myotomy. Endoscopy. Heller myotomy. Gastroesophageal reflux.

\section{INTRODUCTION}

Achalasia is characterized by partial or absent relaxation of the lower esophageal sphincter (LES) and non-peristaltic contractions in the esophageal body ${ }^{(1)}$. It remains an uncommon disease in the general population, with an estimated prevalence of seven to 13 cases per 100,000 individuals ${ }^{(2)}$, but is the most common esophageal motility disorder. In Brazil, the most common etiology is chronic Chagas disease, and it is estimated that it affects approximately $7 \%$ to $10 \%$ of people infected with Trypanosoma cruzi ${ }^{(3)}$. Symptoms related to the disease include regurgitation and dysphagia, caused by obstruction of the alimentary flow to the stomach, in addition to retrosternal pain, likely related to the spasm of the musculature to overcome the obstruction of the $\operatorname{LES}^{(4,5)}$.

There are several less invasive treatment modalities for achalasia, but unfortunately none provide definitive therapy for the disease. In general, the treatment targets relaxation of the LES, as it is felt that the non-relaxation of the LES leads to obstruction of food and thus the subsequent symptoms associated with the disease $^{(6)}$. Traditionally, pharmacological treatment and botulinum toxin injection are used in early cases ${ }^{(7)}$. Until recently, for more advanced cases, pneumatic dilatation by endoscopy and surgical laparoscopic Heller myotomy (LHM) were the indicated treatments. These two modalities had similar efficacy results, however, there was a longer symptom-free period associated with the surgical therapy ${ }^{(8-10)}$

In 2010, Inoue and colleagues described peroral endoscopic myotomy (POEM) as a new modality of treatment for achalasia ${ }^{(11)}$. It combines the benefits of less invasive endoscopic treatment with the durability of surgical therapy, which decreases the need for recurrent procedures in the long term. The procedure consists of making a submucosal tunnel from the middle esophagus to the proximal stomach, followed by total or partial myotomy of the muscle. One major criticism of the procedure is that it does not involve an anti-reflux valve system confection, which might lead to an increased rate of post-procedure reflux in comparison to LHM, which is often paired with a fundoplication at the time of the myotomy ${ }^{(12,13)}$.

To date, only few studies with small sample sizes have aimed to compare outcomes of LHM vs POEM. Randomized clinical trials are still ongoing, yet none are completed to date. Thus, the aim of this study is to perform a systematic review and meta-analysis to compare the efficacy and safety of POEM compared to LHM.

Declared conflict of interest of all authors: none

Disclosure of funding: no funding received

${ }^{1}$ Universidade de São Paulo, Faculdade de Medicina, Hospital das Clínicas, Unidade de Endoscopia, Departamento de Gastroenterologia, São Paulo, SP, Brasil. ${ }^{2}$ Harvard Medical School, Brigham and Women's Hospital, Division of Gastroenterology, Hepatology and Endoscopy, MA, USA.

Corresponding author: Igor Braga Ribeiro. E-mail: igorbraga1@gmail.com 


\section{METHODS}

\section{Protocols and registration}

This systematic review is in accordance with the Preferred Reporting Items for Systematic reviews and Meta-analyses (PRISMA) recommendations and registered on PROSPERO international database (www.crd.york.ac.uk/prospero/) under the number CRD42018085796.

\section{Search strategy}

We conducted a systematic review of the world literature with individualized searches of MEDLINE, EMBASE, Scopus, LILACS, BVS, Cochrane Central Register of Controlled Trials (CENTRAL) from inception through April 2019. The following medical subject heading (MESH) terms were used:

Medline: (esophageal achalasia OR cardiospasm OR achalasia OR megaesophagus) and (POEM OR Peroral endoscopic myotomy or peroral esophageal myotomy or per-oral myotomy) and (Heller myotomy OR laparoscopic myotomy OR surgery myotomy).

EMBASE, Scopus, LILACS, BVS, Cochrane Central Register of Controlled Trials (CENTRAL): esophageal achalasia and POEM and Heller myotomy.

\section{Study eligibility criteria}

We sought and included studies according to the following criteria:

Study type: prospective or retrospective studies with abstract and full text available, regardless of date or language of publication. Study population: all adult patients ( $\geq 18$ years of age) with one of three subtypes of achalasia, with or without prior history of therapy for achalasia.

Types of intervention: Per-Oral Endoscopic Myotomy (POEM) versus surgical cardiomyotomy (Heller).

Outcome measures: Eckardt Score reduction, Post-Operative Eckardt comparison, postoperative gastroesophageal reflux disease (GERD), operative time, overall complication rate, length of hospital stay, postoperative pain score.

\section{Exclusion criteria}

All articles involving pediatric patients and all articles which evaluated the efficacy and safety of treatment of only one of the subtypes of achalasia by manometric classification Chicago ${ }^{(14)}$ were excluded.

\section{Data collection}

All search hits, abstracts, and full texts were evaluated for eligibility by three reviewers independently, who had experience in data extraction for retrospective and prospective studies, by using the predefined inclusion and exclusion criteria. Any differences were resolved via discussion between the three reviewers. If the same research group published more than one article, it was decided to include both studies if there were different or complementary results. The data was included in Excel tables. Data from the studies included first author, year of publication, country, study design, and follow-up time. The outcomes were analyzed in other tables.

\section{Studies quality appraisal}

The Modified Newcastle-Ottawa quality assessment scale was used and scores above 5 were considered satisfactory for the quality evaluation.

\section{Statistical analysis}

Effect sizes for continuous variables were analyzed using the mean difference (MD) and standard deviation (SD) with $95 \%$ confidence interval. For categorical variables, we used the risk difference (RD) with 95\% confidence interval. The RD and MD were considered statistically significant at a $P$-value less than 0.05 . Pooling of continuous data required the mean and SD of each study. However, some of the published clinical trials only reported the size of the trial, the median, and range. Using these available statistics, estimates of the mean and SD were obtained using the Hozo et al. formula ${ }^{(15)}$.

Heterogeneity among studies was assessed using I 2 index introduced by Higgins and Thompson ${ }^{(16)}$. Significant heterogeneity was defined as I $>50 \%$. A random-effect model was used except for when statistical heterogeneity was not significant (i.e. if $\mathrm{I}^{2}<50 \%$, fixed effect model was used.) If necessary, a funnel plot was constructed, and the outsider study was excluded from the analysis.

To analyze the majority of outcomes, RevMan 5.3 was used. However, for the analysis of Eckardt Score reduction, we used Comprehensive Metanalysis Software (version 3.3.070) as it allows an analysis using the pre- and post-values of the Eckardt Score, which cannot be performed in RevMan 5.

\section{RESULTS}

\section{Study selection and characteristics}

The initial search resulted in 387 articles. Twelve were duplicates and were excluded. Twenty-four studies fulfilled initial eligibility criteria. However, of these, nine were descriptive reviews or metaanalyses, one analyzed only type III achalasia, one analyzed only the extension of myotomy, and one was only a descriptive study about post-procedure pain and thus they were excluded from the analysis, resulting in 12 studies for our meta-analysis. All 12 studies were cohort studies, as no randomized clinical trials were available (FIGURE 1).

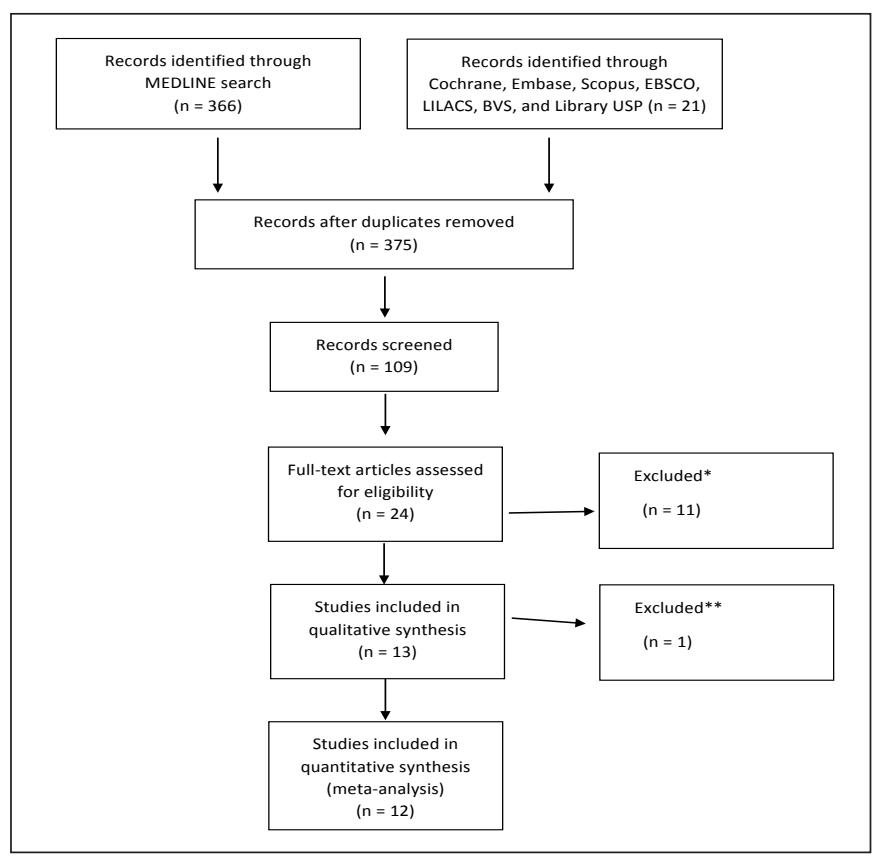

FIGURE 1. Prisma flow chat.

*Other systematic reviews and metanalysis. **Descriptive study about pain. 
Two studies ${ }^{(17,18)}$ were published by the same group on a similar patient population, however, the outcomes analyzed in each study were different and thus they were included in this analysis. Ujiki et al. ${ }^{(19)}$ and Ward et al. ${ }^{(20)}$ are from the same group, but the publications (completed in 2013 and 2017) consisted of a heterogeneous group of patients and had different results, thus both studies were used in this analysis. There were 893 patients overall; 359 in POEM group and 534 in LHM. The study characteristics are summarized in TABLE 1.

\section{Risk of bias}

The risk of bias between studies queue done with Modified New Castle Ottawa, as shown in TABLE 2. All articles were considered adequate for analysis in our study given scores of $\geq 5$.

\section{Therapeutic efficacy}

The main clinical measure of efficacy for treatment of achalasia is the Eckardt score value, which consists of the analysis of weight loss, dysphagia severity, a sensation of retrosternal pain and regurgitation. We found adequate data in 7 of the 12 studies, including 542 patients. When the initial analysis of the Eckardt score reduction was performed, a greater reduction was observed in patients whom underwent POEM compared to LHM, with statistical significance. A Forrest Plot tool was used to investigate the heterogeneity of the sample, and we noticed that two studies ${ }^{(19,21)}$ had significantly different levels of preoperative Eckardt scores between the groups, which may have led to the aforementioned finding of statistically significant reduction in Eckardt score in favor of the POEM cohort. However, when these two studies were excluded from the analysis, there was no longer significant heterogeneity amongst the studies $\left(\mathrm{I}^{2}=25 \%\right)$, yet the result remained the same and continued to favor the POEM group $(\mathrm{MD}=-0.257,95 \% \mathrm{CI}:-0.512$ to $-0.002, P=0.04)$ (FIGURE 2).

TABLE 1 . Study Characteristics

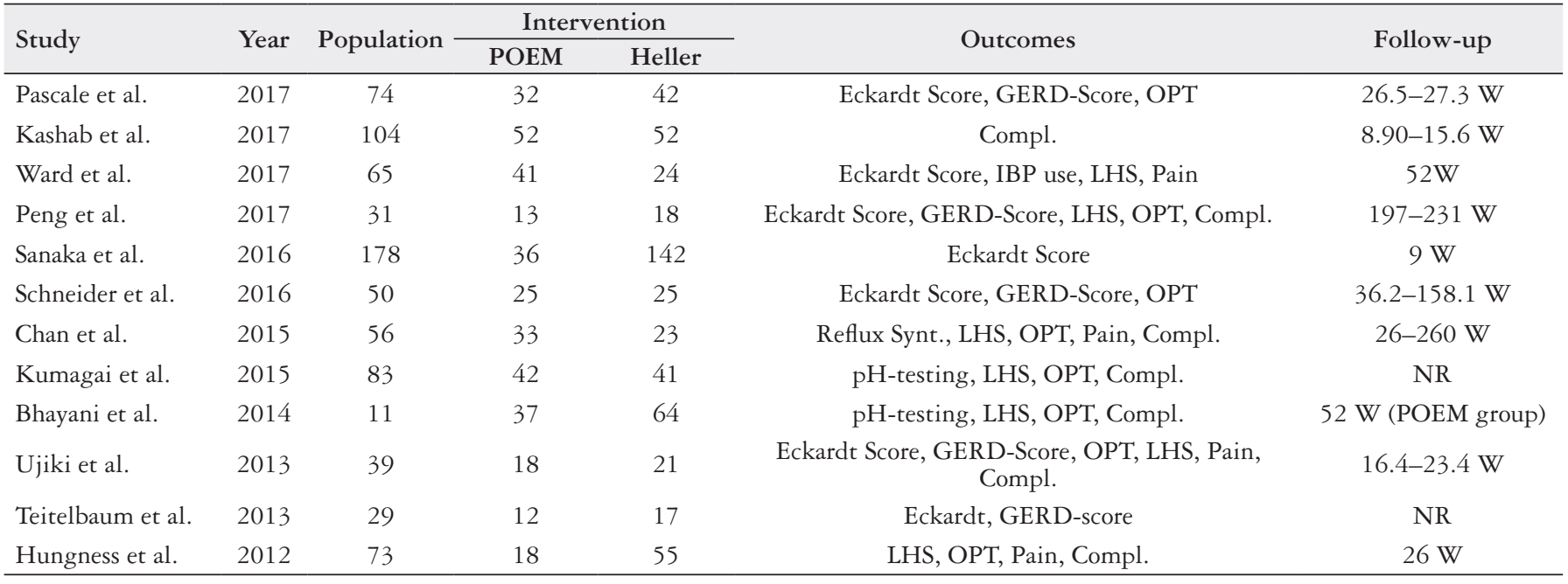

OPT: Operative Time; GERD-Score: Gastroesophageal Reflux Disease Score; Compl.: Complication; LHS: Length of Hospital Stay; W: weeks

TABLE 2. Modified Newcastle-Ottawa Quality Assessment Scale.

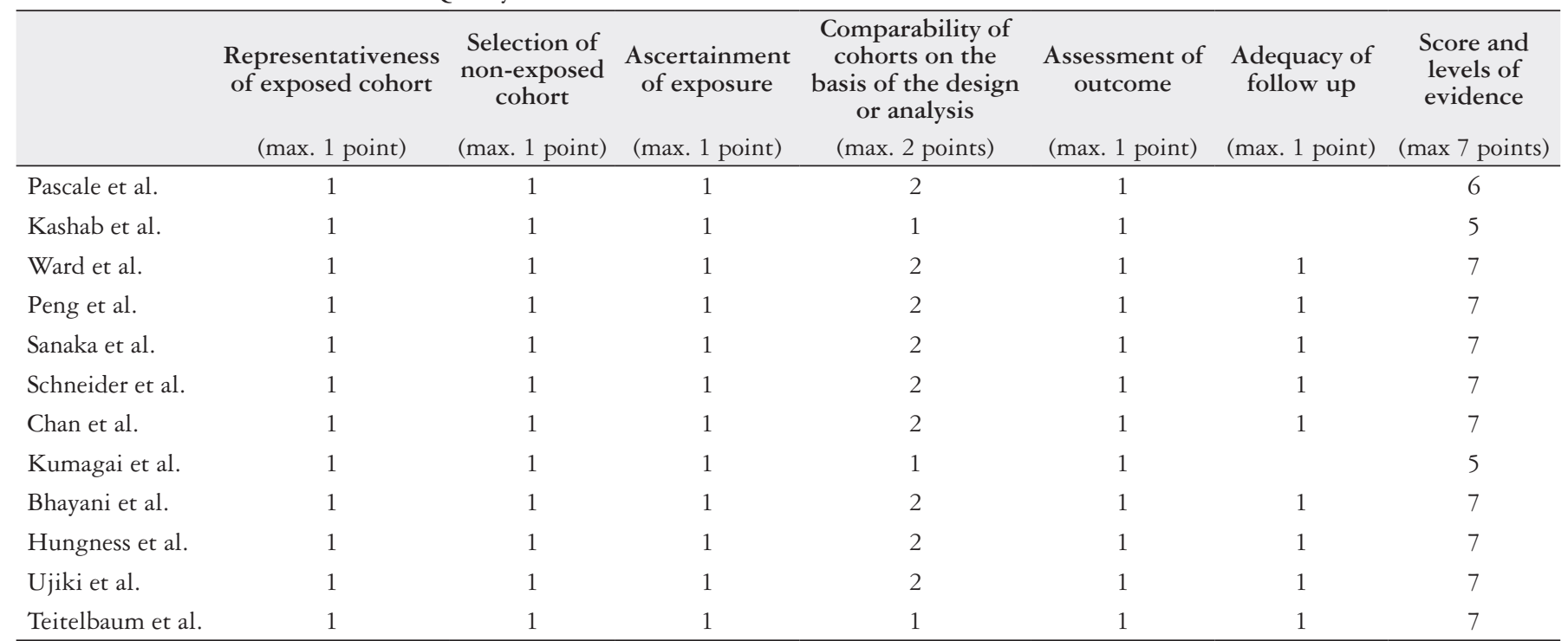

Modified New Castle Ottawa 


\section{Eckardt Sore Reduction}

Study name

$\begin{array}{lrrrrrrr} & \begin{array}{c}\text { Siddff } \\ \text { inmeans }\end{array} & \begin{array}{c}\text { Standard } \\ \text { error }\end{array} & \text { Variance } & \begin{array}{r}\text { Lower } \\ \text { limit }\end{array} & \begin{array}{r}\text { Upper } \\ \text { limit }\end{array} & \begin{array}{l}\text { Z-Value } \\ \text { p-Value }\end{array} \\ \text { Pascale2017 } & 0,000 & 0,235 & 0,055 & -0,460 & 0,460 & 0,000 & 1,000 \\ \text { Werd2017 } & -0,868 & 0,268 & 0,072 & -1,394 & -0,343 & -3,239 & 0,001 \\ \text { Peng 2017 } & -0,289 & 0,366 & 0,134 & -1,006 & 0,428 & -0,789 & 0,430 \\ \text { Schneider 2016 } & -0,077 & 0,283 & 0,080 & -0,631 & 0,478 & -0,272 & 0,786 \\ \text { Teitelbaum2013 } & 0,000 & 0,377 & 0,142 & -0,739 & 0,739 & 0,000 & 1,000 \\ & -0,257 & 0,130 & 0,017 & -0,512 & -0,002 & -1,977 & 0,048\end{array}$

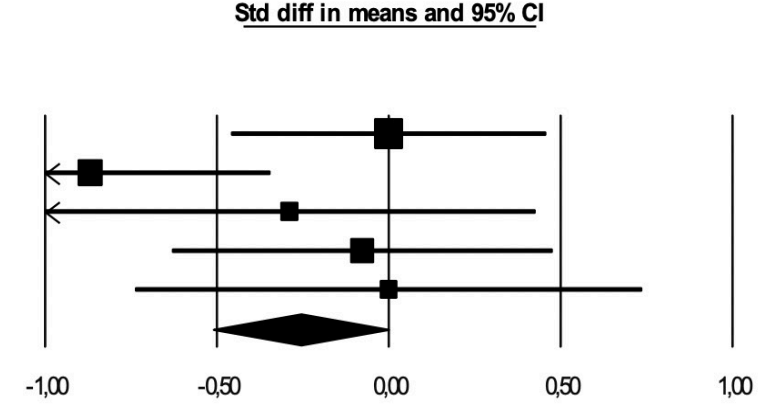

Favars $\mathrm{POEM}$

Favars Heller
FIGURE 2. Eckardt Score Reduction analysis without outliers studies.

\section{Post-operative gastroesophageal reflux}

Seven of the 12 studies were included in the meta-analysis to assess post-procedure gastroesophageal reflux, with a total of 352 patients. Measures for analysis in the various studies included: GERD-score, $\mathrm{pH}$-testing, the presence of symptoms and use of proton pump inhibitor at the end of the study. There was no statistical difference in postoperative reflux (RD: - $0.00,95 \%$ CI: (-0.09, 0.09 ), $\mathrm{I}^{2}: 0 \%, P=0.96$ ) (FIGURE 3).

\section{Operative time}

Seven of the 12 studies allowed for analysis of operative time, with a total of 422 patients. There was no statistical difference between the techniques regarding the operative time $(\mathrm{MD}=-10.26$, $95 \%$ CI -5.6 to $8.2, P<0.001$ ) (FIGURE 4).

\section{Length of hospital stay}

Data for analysis of hospitalization time were available in 7 of

\begin{tabular}{|c|c|c|c|c|c|c|c|c|}
\hline \multirow[b]{2}{*}{ Study or Subgroup } & \multicolumn{2}{|c|}{ POEM } & \multicolumn{2}{|c|}{ Heller } & \multirow[b]{2}{*}{ Weight } & \multirow{2}{*}{$\begin{array}{l}\text { Risk Difference } \\
\text { M-H, Fixed, } 95 \% \mathrm{Cl}\end{array}$} & \multirow{2}{*}{\multicolumn{2}{|c|}{$\begin{array}{l}\text { Risk Difference } \\
\text { M-H, Fixed, } 95 \% \mathrm{Cl}\end{array}$}} \\
\hline & Events & Total & Events & Total & & & & \\
\hline Bhayani NH 2015 & 9 & 23 & 10 & 31 & $15.3 \%$ & $0.07[-0.19,0.33]$ & & \\
\hline Chan SM 2016 & 5 & 33 & 6 & 23 & $15.7 \%$ & $-0.11[-0.33,0.11]$ & & \\
\hline Kumagai K 2015 & 7 & 42 & 7 & 41 & $24.1 \%$ & $-0.00[-0.17,0.16]$ & & \\
\hline Pascale 2017 & 5 & 18 & 4 & 18 & $10.4 \%$ & $0.06[-0.23,0.34]$ & & \\
\hline Peng L 2017 & 1 & 13 & 1 & 18 & $8.8 \%$ & $0.02[-0.16,0.20]$ & & \\
\hline Teitelbaum EN 2013 & 2 & 12 & 5 & 17 & $8.2 \%$ & $-0.13[-0.43,0.17]$ & & \\
\hline Ward MA 2017 & 19 & 41 & 10 & 24 & $17.6 \%$ & $0.05[-0.20,0.30]$ & & \\
\hline Total $(95 \% \mathrm{Cl})$ & & 182 & & 172 & $100.0 \%$ & $-0.00[-0.09,0.09]$ & & \\
\hline Total events & 48 & & 43 & & & & & \\
\hline $\begin{array}{l}\text { Heterogeneity: } \mathrm{Chi}^{2}= \\
\text { Test for overall effect: }\end{array}$ & $\begin{array}{l}26, d f=E \\
=0.05(P\end{array}$ & $\begin{array}{l}(P=0 . \\
=0.96\end{array}$ & $89) ; 1^{2}=0$ & & & & $\begin{array}{cc}-0.5 & 0 \\
\text { Favours (POEM) } & \text { Favours }\end{array}$ & $\begin{array}{l}0.5 \\
\text { (Heller) }\end{array}$ \\
\hline
\end{tabular}

FIGURE 3. Post-Operative Gastroesophageal Reflux.

\begin{tabular}{|c|c|c|c|c|c|c|c|c|c|c|c|c|}
\hline \multirow[b]{2}{*}{ Study or Subgroup } & \multicolumn{3}{|c|}{ POEM } & \multicolumn{3}{|c|}{ Heller } & \multirow[b]{2}{*}{ Weight } & \multirow{2}{*}{$\begin{array}{l}\text { Mean Difference } \\
\text { IV, Random, } 95 \% \mathrm{Cl}\end{array}$} & \multirow{2}{*}{\multicolumn{4}{|c|}{$\begin{array}{l}\text { Mean Difference } \\
\text { IV, Random, } 95 \% \mathrm{Cl}\end{array}$}} \\
\hline & Mean & SD & Total & Mean & SD & Total & & & & & & \\
\hline Bhayani NH 2015 & 128.7 & 38.7 & 37 & 175 & 45 & 64 & $13.4 \%$ & $-46.30[-62.94,-29.66]$ & & & & \\
\hline Chan SM 2016 & 97 & 40.8 & 33 & 127 & 30.1 & 23 & $12.8 \%$ & $-30.00[-48.58,-11.42]$ & & & & \\
\hline Hungness ES 2012 & 133.5 & 33 & 18 & 133.7 & 26.2 & 55 & $13.4 \%$ & $-0.20[-16.94,16.54]$ & & & & \\
\hline Kumagai K 2015 & 130.2 & 32.7 & 42 & 108.5 & 17 & 41 & $14.9 \%$ & $21.70[10.53,32.87]$ & & & -- & \\
\hline Peng L 2017 & 93.4 & 23.5 & 13 & 121.3 & 20.1 & 18 & $13.7 \%$ & $-27.90[-43.69,-12.11]$ & & & & \\
\hline Schneider AM 2016 & 155.8 & 12.8 & 18 & 154.5 & 8.3 & 21 & $15.9 \%$ & $1.30[-5.60,8.20]$ & & & - & \\
\hline Ujiki MB 2013 & 155.8 & 12.8 & 18 & 154.5 & 8.3 & 21 & $15.9 \%$ & $1.30[-5.60,8.20]$ & & & - & \\
\hline & & & 179 & & & 243 & $100.0 \%$ & $-10.26[-24.44,3.93]$ & & & & \\
\hline \multicolumn{8}{|c|}{$\begin{array}{l}\text { Heterogeneity: } \operatorname{Tau}^{2}=318.06 ; \mathrm{Chi}^{2}=65.35, \mathrm{df}=6(\mathrm{P}<0.00001) ; \mathrm{I}^{2}=91 \% \\
\text { Test for overall effect: } Z=1.42(P=0.16)\end{array}$} & & -100 & $\begin{array}{c}-50 \\
\text { Favours [POEM] }\end{array}$ & $\begin{array}{cc}0 & 50 \\
] & 1 \\
\text { Favours [Heller] }\end{array}$ & 100 \\
\hline
\end{tabular}

FIGURE 4. Operative time. 
the 12 studies, with a total of 451 patients. It was observed that those who underwent endoscopic myotomy had shorter hospitalization time than the patients submitted to the surgical procedure (MD: $-0.6,95 \%$ CI -1.11 to $-0.09, P=0.02)$, but with high heterogeneity $\left(\mathrm{I}^{2}=70 \%\right)($ FIGURE 5).

\section{Adverse events}

To analyze procedural-related adverse events, Clavien-Dindo (CD) classification was established to standardize the data. Seven studies provided adequate data for analysis. Two studies provided the classification specifically (Kumagai et al.(22) and Hungness et al. $\left.{ }^{(18)}\right)$, while others provided data and the present authors classified them accordingly (Khashab et al. ${ }^{(23)}$, Peng et al. ${ }^{(24)}$, Chan et al. ${ }^{(25)}$, Bhayani et al. ${ }^{(26)}$, Ujiki et al. $\left.{ }^{(19)}\right)$.

There was no severe adverse event in either group, as observed in TABLE 3. Minor adverse events (CD I and II) were more frequent in the laparoscopic group, while major events (CD III a and IIIb) were more common in the POEM group, with a total of 7 events (TABLE 3). There were no deaths related to the procedures.

\section{DISCUSSION}

The goal of treatment of achalasia is reduction of lower esophageal sphincter pressure, through pharmacologic relaxation or more invasive dissection or splitting of the LES muscular fibers through a variety of diverse techniques. Until recently, the gold standard for definitive treatment was surgical myotomy, consisting of a controlled partial or full thickness dissection of muscle fibers, in addition to partial fundoplication to reduce the incidence of post-procedure gastroesophageal reflux disease. In 2010, Inoue and colleagues first published on the use of POEM in humans ${ }^{(11)}$, and it has since been shown in many small studies to have similar safety and efficacy results in comparison to LHM.

Our meta-analysis revealed that the patients whom underwent POEM had better symptomatic relief than those whom underwent LHM. While prior systematic reviews and meta-analysis have not elucidated this same finding. This is likely due to the small number of patients included in those studies with short term follow-up, and thus lack of power to demonstrate a significant result ${ }^{(27-29)}$. There was only one study, by Peng et al. ${ }^{(24)}$, which had follow-up time greater than 12 months. In this study, the authors demonstrated that there was no statistically significant differences between values of Eckardt scores in the POEM vs LHM groups at the end of the study period. They also demonstrated that a satisfactory therapeutic response occurred in more than $80 \%$ of the patients overall without statistically significant differences between the groups. A similar result was observed in a recent meta-analysis ${ }^{(30)}$, which compared isolated case series of POEM vs LHM, where the authors demonstrated that in the short-term POEM technique had better results, but when the follow-up was greater than 1 year, the result tended to be the same between the two groups.

There are several cases series with longer follow-up time which showed that the efficacy of POEM is sustained over time. Inoue et al. ${ }^{(31)}$ published a case series with up to 3-year follow-up and showed a persistent reduction in Eckardt score in this period. Ngamruengphong $\mathrm{S}$ et al. ${ }^{(32)}$, in a multicenter study, reported an efficacy of $91 \%$ (defined as Eckardt $<3$ ) at the end of a 2-year follow-up period. $\mathrm{Li}$ QL et al. ${ }^{(33)}$ demonstrated an efficacy of $87.1 \%$ at the end of a 5-year follow-up period. These authors were the first to demonstrate that previous intervention prior to POEM or LHM and longer duration of disease could be possible causes of therapeutic failure. Thus, from these prior studies is evident that symptomatic improvement

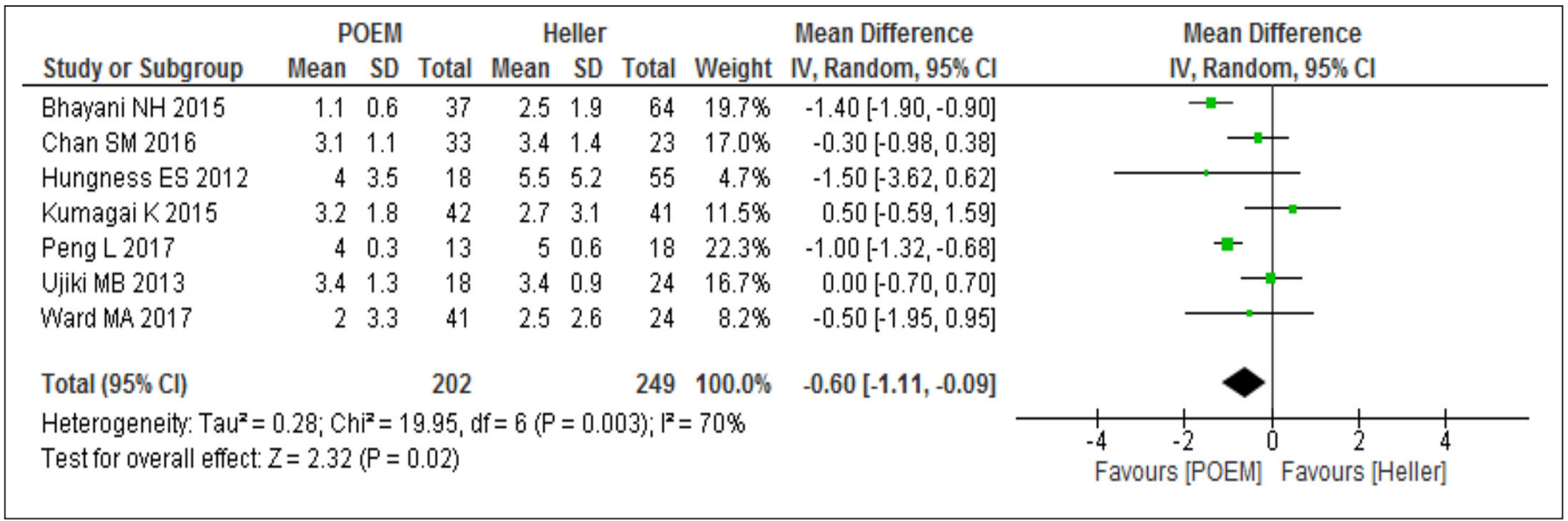

FIGURE 5. Length of hospital stay.

TABLE 3. Adverse events after procedure.

\begin{tabular}{|c|c|c|c|c|c|c|c|c|c|c|c|c|c|c|}
\hline \multirow[b]{2}{*}{ Clavien-Dindo } & \multicolumn{2}{|c|}{ Kashab et al. } & \multicolumn{2}{|c|}{ Peng et al. } & \multicolumn{2}{|c|}{ Chan et al. } & \multicolumn{2}{|c|}{ Kumagai et al. } & \multicolumn{2}{|c|}{ Bhayani et al. } & \multicolumn{2}{|c|}{ Uijiki et al. } & \multicolumn{2}{|c|}{ Hungness et al. } \\
\hline & POEM & Heller & POEM & Heller & POEM & Heller & POEM & Heller & POEM & Heller & POEM & Heller & POEM & Heller \\
\hline I & & 1 & & 1 & & & & & & & 1 & & 3 & 7 \\
\hline IIIa & 1 & & 1 & & 1 & & & & & & & & & \\
\hline IIIb & & & & & & & 1 & 1 & 1 & 1 & 1 & 1 & 1 & 1 \\
\hline
\end{tabular}


based on long-term Eckardt score reduction is similar between those patients treated with POEM vs LHM, and long-term studies demonstrate that this outcome appears to be sustained.

In this systematic review, post-POEM reflux ranged from $7.5 \%$ to $47 \%$, whereas for surgical myotomy reflux ranged from $5.6 \%$ to $43 \%$, which was not statistically significantly different between the groups. These rather broad ranges are likely related to the heterogeneity amongst the studies in terms of the mode by which post-procedure reflux was analyzed. There is a clear dissociation between the presence or absence of reflux symptoms and the finding or absence of pathological reflux measured by objective measures (pH-testing) and endoscopic analysis. Inoue et al. ${ }^{(31)}$ reported endoscopic findings consistent with reflux in $56.3 \%$ of patients, while only $21.3 \%$ of patients reported symptoms consistent with reflux disease. All patients had symptomatic control with the use of a proton-pump inhibitor. In the study published by Pascale et al. ${ }^{(34)}$, only $12.5 \%$ of patients after POEM were symptomatic, whereas esophagitis and endoscopy findings reached 40\%. Scheneider et al. ${ }^{(35)}$ demonstrated a $54.3 \%$ rate of esophagitis in the postoperative endoscopy of POEM. Teitelbaum et. al., in a large multi-center study ${ }^{(17)}$ of patients whom underwent POEM, demonstrated a change in pH-testing of $57.8 \%$ and $37.5 \%$ at the end of one-year and two-year follow up, respectively.

One case series meta-analysis ${ }^{(30)}$ with the largest number of patients, used patient reported symptoms to demonstrate that the two procedures cause comparable rates of symptoms indicative of post-procedure reflux disease. However, when evaluated on postoperative endoscopy, there was a greater number of patients with esophagitis (22.4 versus $11.5 \%)$ in patients whom underwent POEM; when evaluated on $\mathrm{pH}$-testing, reflux was present in up to $47.5 \%$ of the patients whom underwent POEM compared to only $11.1 \%$ in the surgical myotomy group. Notably, almost all of the published studies to date have high rates of patients whom are lost to follow-up, which most certainly impacts data analysis. It is of our opinion that standardization in measurement must occur in this patient population. While use of 24-hour $\mathrm{pH}$ and impedance testing can be limited given requirement of placement and removal of the catheter in a healthcare setting, we believe this should be the established standard for post-operative reflux analysis.

Regarding operative time, only one study ${ }^{(22)}$ demonstrated longer operative time for POEM, and the author thinks that this was related to a learning curve of the endoscopists. All other studies demonstrated a shorter procedure time in the POEM group. Additionally, our analysis demonstrated that POEM is associated with a shorter length of hospital stay. Thus, as providers continue to gain more experience with POEM, the hope is that the procedure time and length of stay will continue to improve. As both of these factors contribute to hospital costs, with ongoing experience and improvement in these parameters, it may lead to decreased healthcare utilization and expenditure over time.

In terms of adverse events, there is no standardized classification system for comparison, thus we chose to use the ClavienDindo classification for its simplicity and clarity ${ }^{(36)}$. Our study demonstrated a low rate of adverse events and no reported deaths. Notably, subcutaneous emphysema and inadvertent mucosal perforation were not classified as adverse events, unless they were not immediately recognized and/or required procedures beyond the normal intraoperative interventions. Unfortunately, most of the major adverse events were related to unrecognized intraoperative mucosal perforation. Some recent studies ${ }^{(7,37,38)}$ found no difference in adverse events or efficacy after treatment with POEM vs Heller in patients treated with different previous therapies (dilation, Botox, and surgery $)^{(4,7,21,38-41)}$. However, a separate prior study by Ren et al. ${ }^{(42)}$ showed a higher complication rate in POEM, perhaps related to the learning curve. More recently, experienced endoscopists have shown very low complication rates in POEM, such as Inoue et al. ${ }^{(31)}$ and Zhang $\mathrm{XC}^{(43)}$ et al., which demonstrated $3.2 \%$ and $3.3 \%$ of major adverse events, respectively. In the largest study ever published, with 1826 patients whom underwent POEM, including American, European, and Asian studies, the rate of adverse events was $7.5 \%$, and of these, only four patients required conversion to surgery ${ }^{(12)}$. In our study, we observed comparable low adverse events rates in the POEM and LHM groups, thus from a safety perspective, either procedure can be considered in the management options of achalasia.

Five of 12 studies describe peri- or postoperative pain, but the report of pain is quite heterogeneous, which does not allow accurate meta-analysis. Ward et al. ${ }^{(20)}$ evaluated postoperative pain according to an analog pain scale and the need for analgesic medication at hospital discharge. They observed that there was less pain at hospital discharge in patients whom underwent POEM compared to LHM. By analyzing visual pain scale and analgesic medication requirement, Docimo S Jr et al. ${ }^{(4)}$ found significantly less pain in POEM patients. Chan et al. ${ }^{(25)}$ evaluated the need for postoperative pentamidine and found that patients undergoing LHM required more medication. Hungness et al. ${ }^{(18)}$ evaluated the level of pain in the recovery unit and in the first postoperative period, noting no difference between the groups, and Ujiki et al. ${ }^{(19)}$ demonstrated a better result for the POEM cohort by comparing both the need for morphine derivatives and the visual analog pain scale. Thus, based on these studies, one can argue that POEM patients seem to have less pain than LHM patients, although additional comparator studies and a standardized way of measurement must be done to confirm this finding.

\section{Limitations}

Our study has some limitations due to heterogeneity among the studies. Only one study had a follow-up period of greater than 12 months, making it impossible to evaluate long-term outcomes in this review. Randomized trials comparing methods are not available yet in the literature, which reduces the level of evidence from this review.

\section{CONCLUSION}

POEM demonstrated similar results compared to laparoscopic Heller myotomy with regards to improvement of dysphagia, postprocedure reflux, and surgical time, with the benefit of shorter length of hospital stay. Therefore, POEM can be considered an option for patients with achalasia.

\section{Authors' contribution}

Martins RK HP acquisition of data, analysis, interpretation of data, drafting the article, revising the article, final approval; 
de Moura DTH analysis and interpretation of data, drafting the article, final approval; Ribeiro IB acquisition of data, drafting the article, revising the article, final approval; Bernardo WM, de Moura DTH and Ribeiro IB: analysis and interpretation of data, revising the article; Hathorn, KE: analysis and interpretation of data, drafting the article, revising the article, final approval; de Moura EGH: conception and design of the study, critical revision, final approval.

\section{Orcid}

Rafael Krieger Martins: 0000-0002-6135-5759.

Diogo Turiani Hourneaux de Moura: 0000-0002-7446-0355.

Igor Braga Ribeiro: 0000-0003-1844-8973.

Kelly E. Hathorn: 0000-0002-5677-7383.

Wanderley Marques Bernardo: 0000-0002-8597-5207.

Eduardo Guimarães Hourneaux de Moura: 0000-0002-8023-3722.

Martins RK, Ribeiro IB, de Moura DTH, Hathorn KE, Bernardo WM, de Moura EGH. Miotomia peroral (POEM) ou cirúrgica para o tratamento da acalasia: revisão sistemática e metanálise. Arq Gastroenterol. 2020;57(1):79-86.

RESUMO - Contexto - A acalasia é um distúrbio esofágico da motilidade neurodegenerativa caracterizado por falha no relaxamento do esfíncter esofágico inferior (EEI). A opção de tratamento convencional para acalasia tem sido a miotomia laparoscópica de Heller (LHM). No entanto, em 2010, Inoue et al. descreveram a miotomia endoscópica peroral (POEM), um procedimento minimamente invasivo, como uma terapia alternativa. Até o momento, poucos estudos com amostras pequenas tiveram como objetivo comparar os resultados do LHM versus POEM. Objetivo - Assim, o objetivo deste estudo é realizar uma revisão sistemática e metanálise para melhor avaliar a eficácia e segurança dessas duas técnicas. Métodos - Estratégias de busca individualizadas foram desenvolvidas desde o início até abril de 2019, de acordo com as diretrizes do PRISMA. As variáveis analisadas incluíram tempo operatório, taxa global de eventos adversos, doença de refluxo gastroesofágico (DRGE) pós-procedimento, tempo de internação, escore de dor pós-procedimento e redução do escore de Eckardt. Resultados - Doze estudos de coorte foram selecionados, consistindo em 893 pacientes (359 no grupo POEM e 524 no LHM). Nenhum ensaio clínico randomizado estava disponível. Não houve diferença no tempo operatório (MD = -10,26, IC $95 \%$ (-5,6 a 8,2), $P<0,001)$ ou refluxo gastroesofágico pós-operatório (RD: -0,00, 95\% IC: (-0,09, 0,09), I2: 0\%). Houve diminuição do tempo de permanência hospitalar para POEM (MD: - $0,6,95 \%$ CI $(-1,11,-0,09), P=0,02)$ e um aumento da redução média no escore de Eckardt em pacientes POEM (MD= -0,257, IC95\%: (-0,512 a -0,002), $P=0,048)$, com taxas similares de eventos adversos. Conclusão - O POEM demonstrou resultados semelhantes aos da miotomia a Heller por videolaparoscopia, com melhora da disfagia, do refluxo pós-procedimento e tempo cirúrgico, com o benefício de menor tempo de internação hospitalar. Portanto, o POEM pode ser considerado uma opção para pacientes com acalasia.

DESCRITORES - Acalásia esofágica. Miotomia. Endoscopia. Miotomia de Heller. Refluxo gastroesofágico.

\section{REFERENCES}

1. Wong RKH MC. Achalasia. In: Castell DO, Richter JE, editoes. The esophagus. 3rd ed. Philadelphia: Lippincott Williams \& Wilkins; 1999: 1999.

2. Martins-Melo FR. Epidemiologia e distribuição espacial da mortalidade relacionada à doença de Chagas no Brasil, 1999 a 2007. Cad Saúde Colet. 2013;21:105-6. doi: http://dx.doi.org/10.1590/S1414-462X2013000100017.

3. Malafaia G, de Lima Rodrigues AS. Centenário do descobrimento da doença de chagas: Desafios e perspectives. Rev Soc Bras Med Trop. 2010;43:483-5. [Internet]. Available from: http://www.scielo.br/scielo.php?script=sci_arttext\&pid=S0037-86822010000500001\&lng=pt\&tlng=pt

4. Vaezi MF, Felix VN, Penagini R, Mauro A, de Moura EGH, Pu LZCT, et al Achalasia: from diagnosis to management. Ann N Y Acad Sci. 2016;1381:34-44.

5. Josino IR, Madruga-Neto AC, Ribeiro IB, Guedes HG, Brunaldi VO, de Moura DTH, et al. Endoscopic Dilation with Bougies versus Balloon Dilation in Esophageal Benign Strictures: Systematic Review and Meta-Analysis. Gastroenterol Res Pract. 2018;2018:1-9.

6. Friedel D, Modayil R, Stavropoulos SN. Per-oral endoscopic myotomy: Major advance in achalasia treatment and in endoscopic surgery. World J Gastroenterol. 2014;20:17746-55.

7. Orenstein SB, Raigani S, Wu Y V., Pauli EM, Phillips MS, Ponsky JL, Marks JM. Peroral endoscopic myotomy (POEM) leads to similar results in patients with and without prior endoscopic or surgical therapy. Surg Endosc. 2015;29: 1064-70.

8. Boeckxstaens GE, Annese V, Varannes SB des, Chaussade S, Costantini M, Cuttitta A, et al. Pneumatic Dilation versus Laparoscopic Heller's Myotomy for Idiopathic Achalasia. N Engl J Med. 2011;364:1807-16.

9. De Moura ETH, De Moura EGH. Endoscopic pneumatic dilatation and peroral endoscopic myotomy in dilated megaesophagus. Mini-invasive Surg. 2017; [DOI: 10.20517/2574-1225.2017.27]. Available from: http://misjournal.net/article/ view/2171

10. Moura EGH, Maluf Filho F, Sakai P, Ishioka S. Pneumatic dilatation of cardia in patients with Chagas megaesophagus. GED Gastroenterol Endosc Dig. 1991;10:83-6.
11. Inoue H, Minami H, Kobayashi Y, Sato Y, Kaga M, Suzuki M, Satodate H, Odaka N, Itoh H, Kudo S. Peroral endoscopic myotomy (POEM) for esophageal achalasia. Endoscopy [Internet] 2010;42:265-71.

12. Haito-Chavez Y, Inoue H, Beard KW, Draganov PV, Ujiki M, Rahden BHA, et al. Comprehensive Analysis of Adverse Events Associated with per Oral Endoscopic Myotomy in 1826 Patients: An International Multicenter Study. Am J Gastroenterol. 2017;112:1267-76.

13. Coronel MA, Bernardo WM, de Moura DTH, de Moura EGHE, Ribeiro IB, de Moura HETH, Moura ETH de GH de. The efficacy of the different endoscopic treatments versus sham, pharmacologic or surgical methods for chronic gastroesophageal reflux disease: a systematic review and meta-analysis. Arq Gastroenterol. 2019;55:296-305

14. Kahrilas PJ, Bredenoord AJ, Fox M, Gyawali CP, Roman S, Smout AJPM, Pandolfino JE, International High Resolution Manometry Working Group. The Chicago Classification of esophageal motility disorders, v3.0. Neurogastroenterol Motil. 2015;27:160-74.

15. Hozo SP, Djulbegovic B, Hozo I. Estimating the mean and variance from the median, range, and the size of a sample. BMC Med Res Methodol. 2005;5:13.

16. Higgins JPT, Thompson SG. Quantifying heterogeneity in a meta-analysis. Stat Med. 2002;21:1539-58.

17. Teitelbaum EN, Soper NJ, Santos BF, Arafat FO, Pandolfino JE, Kahrilas PJ, Hirano I, Hungness ES. Symptomatic and physiologic outcomes one year after peroral esophageal myotomy (POEM) for treatment of achalasia. Surg Endosc. 2014;28:3359-65.

18. Hungness ES, Teitelbaum EN, Santos BF, Arafat FO, Pandolfino JE, Kahrilas PJ, Soper NJ. Comparison of Perioperative Outcomes Between Peroral Esophageal Myotomy (POEM) and Laparoscopic Heller Myotomy. J Gastrointest Surg. 2013;17:228-35.

19. Ujiki MB, Yetasook AK, Zapf M, Linn JG, Carbray JM, Denham W. Peroral endoscopic myotomy: A short-term comparison with the standard laparoscopic approach. Surg (United States). 2013;154:893-900. 
20. Ward MA, Gitelis M, Patel L, Vigneswaran Y, Carbray J, Ujiki MB. Outcomes in patients with over 1-year follow-up after peroral endoscopic myotomy (POEM). Surg Endosc. 2017;31:1550-7.

21. Sanaka MR, Hayat U, Thota PN, Jegadeesan R, Ray M, Gabbard SL, et al. Efficacy of peroral endoscopic myotomy vs other Achalasia treatments in improving esophageal function. World J Gastroenterol. 2016;22:4918-25.

22. Kumagai K, Tsai JA, Thorell A, Lundell L, Håkanson B. Per-oral endoscopic myotomy for achalasia. Are results comparable to laparoscopic Heller myotomy? Scand J Gastroenterol. 2015;50:505-12.

23. Khashab MA, Kumbhari V, Tieu AH, El Zein MH, Ismail A, Ngamruengphong $\mathrm{S}$, et al. Peroral endoscopic myotomy achieves similar clinical response but incurs lesser charges compared to robotic heller myotomy. Saudi J Gastroenterol 2017;23:91-6.

24. Peng L, Tian S, Du C, Yuan Z, Guo M, Lu L. Outcome of Peroral Endoscopic Myotomy (POEM) for treating achalasia compared with Laparoscopic Heller Myotomy (LHM). Surg Laparosc Endosc Percutaneous Tech. 2017;27:60-4.

25. Chan SM, Wu JCY, Teoh AYB, Yip HC, Ng EKW, Lau JYW, Chiu PWY Comparison of early outcomes and quality of life after laparoscopic Heller's cardiomyotomy to peroral endoscopic myotomy for treatment of achalasia. Dig Endosc. 2016;28:27-32.

26. Bhayani NH, Kurian AA, Dunst CM, Sharata AM, Rieder E, Swanstrom LL. A comparative study on comprehensive, objective outcomes of laparoscopic heller myotomy with Per-Oral Endoscopic Myotomy (POEM) for achalasia. Ann Surg. 2014;259:1098-103.

27. Awaiz A, Yunus RM, Khan S, Memon B, Memon MA. Systematic Review and Meta-Analysis of Perioperative Outcomes of Peroral Endoscopic Myotomy (POEM) and Laparoscopic Heller Myotomy (LHM) for Achalasia [Internet]. Surg. Laparosc. Endosc. Percutaneous Tech. 2017;27:123-31.

28. Marano L, Pallabazzer G, Solito B, Santi S, Pigazzi A, De R, Biondo FG, Spazian A, Longaroni M, Di N, Boccardi V, Patriti A. Surgery or peroral esophageal myotomy for Achalasia: A systematic review and meta-analysis. Med (United States). 2016;95:e3001.

29. Zhang Y, Wang H, Chen X, Liu L, Wang H, Liu B, Guo J, Jia H. Per-Oral Endoscopic Myotomy Versus Laparoscopic Heller Myotomy for Achalasia. Med (United States). 2016;95:e2736.

30. Schlottmann F, Luckett DJ, Fine J, Shaheen NJ, Patti MG. Laparoscopic Heller Myotomy Versus Peroral Endoscopic Myotomy (POEM) for Achalasia: A Systematic Review and Meta-analysis. Ann Surg. 2018;267:451-60.

31. Inoue H, Sato H, Ikeda H, Onimaru M, Sato C, Minami H, et al. Per-Oral Endoscopic Myotomy: A Series of 500 Patients. J Am Coll Surg. 2015;221:256-64.
32. Ngamruengphong S, Inoue H, Chiu PWY, Yip HC, Bapaye A, Ujiki M, et al. Long-term outcomes of per-oral endoscopic myotomy in patients with achalasia with a minimum follow-up of 2 years: an international multicenter study. Gastrointest Endosc. 2017;85:927-933.e2.

33. Li QL, Wu QN, Zhang XC, Xu MD, Zhang W, Chen SY, et al. Outcomes of peroral endoscopic myotomy for treatment of esophageal achalasia with a median follow-up of 49 months. Gastrointest Endosc. 2018;87:1405-12.e3.

34. de Pascale S, Repici A, Puccetti F, Carlani E, Rosati R, Fumagalli U. Peroral endoscopic myotomy versus surgical myotomy for primary achalasia: single-center, retrospective analysis of 74 patients. Dis Esophagus. 2017;30:1-7.

35. Schneider AM, Louie BE, Warren HF, Farivar AS, Schembre DB, Aye RW. A Matched Comparison of Per Oral Endoscopic Myotomy to Laparoscopic Heller Myotomy in the Treatment of Achalasia. J Gastrointest Surg. 2016;20:1789-96.

36. Clavien PA, Barkun J, De Oliveira ML, Vauthey JN, Dindo D, Schulick RD, et al. The clavien-dindo classification of surgical complications: Five-year experience. Ann Surg. 2009;250:187-96.

37. Tang X, Gong W, Deng Z, Zhou J, Ren Y, Zhang Q, et al. Feasibility and safety of peroral endoscopic myotomy for achalasia after failed endoscopic interventions. Dis Esophagus. 2017;30:1-6.

38. Jones EL, Meara MP, Pittman MR, Hazey JW, Perry KA. Prior treatment does not influence the performance or early outcome of per-oral endoscopic myotomy for achalasia. Surg Endosc. 2016;30:1282-6.

39. de Moura EGH, Ribeiro IB, Frazão MSV, Mestieri LHM, de Moura DTH, Dal Bó CMR. EUS-Guided Intragastric Injection of Botulinum Toxin A in the Preoperative Treatment of Super-Obese Patients: a Randomized Clinical Trial. Obes Surg. 2019;29:32-9.

40. Jankovic J. Botulinum toxin: State of the art. Mov Disord. 2017;32:1131-8.

41. Ribeiro IB, de Moura DTH, de Moura EGH. Response to Letter to the Editor Re: 'EUS-Guided Intragastric Injection of Botulinum Toxin A in the Preoperative Treatment of Super-Obese Patients: a Randomized Clinical Trial'. Obes Surg. 2019;29:1016-7.

42. Ren Z, Zhong Y, Zhou P, Xu M, Cai M, Li L, et al. Perioperative management and treatment for complications during and after peroral endoscopic myotomy (POEM) for esophageal achalasia (EA) (data from 119 cases). Surg Endosc. 2012;26:3267-72.

43. Zhang XC, Li QL, Xu MD, Chen SY, Zhong YS, Zhang YQ, et al. Major perioperative adverse events of peroral endoscopic myotomy: a systematic 5-year analysis. Endoscopy. 2016;48:967-78.

44. Docimo S, Mathew A, Shope AJ, Winder JS, Haluck RS, Pauli EM. Reduced postoperative pain scores and narcotic use favor per-oral endoscopic myotomy over laparoscopic Heller myotomy. Surg Endosc. 2017;31:795-800. 